\title{
Entre prudentes y discretos. La conservación de la Monarquía Católica ante el Tratado de Repartición de 1700
}

\author{
IGNACIO M. ${ }^{\text {a VICENT LÓPEZ }}$
}

La diferenciación política y cultural de la Monarquía Católica leída en términos de decadencia a partir de la Paz de los Pirineos, e iniciada en Westfalia (1648) ${ }^{1}$, acabó relegándola en la conciencia y práctica política europea, de la ilustración dieciochesco, a la categoria de un menor sobre el que debia ejercerse tutela ${ }^{2}$. Hasta el punto de declararse asi ya en 1694 en consejo al propio monarca católico: «toda Europa señor define por Capital raíz de nuestros males la tenacidad con que conservamos nuestros estilos" ${ }^{3}$.

En este proceso pocos momentos en la historia de la Monarquia resultaron, al menos en apariencia, de una trascendencia semejante a los vividos durante el otoño de 1700 . Las incertidumbres que habia de producir $y$, de hecho produjo, la muerte del rey Carlos II sin descendencia directa, interrumpian dos siglos en que la institución monárquica había venido sirviendo de forma ejemplar a una ingente cantidad de territorios, con su principal virtud, la de garantizar la continuidad pacífica en el ejercicio del poder supremo sobre la república. Virtud que, además, era prácticamente la única que desde Castilla podía llegarse a invocar como justificación del gobierno monárquico en obra de consecuente dedicatoria al Príncipe Luis, sin importar la paradoja de escribirse a la vuelta de la Guerra de Sucesión que, al fin y a la postre, había resuelto la crisis sucesoria ${ }^{4}$.

Universidad Autónoma de Madrid.

VIEJO, J., "Ausencia de politica: Ordenación interna y proyecto europeo en la Monarchía Cathólica de mediados del siglo xviı». págs, 15 y ss, en Jornadas de Historia Moderna, 1996.

Fernande. 2 Al bal.adejo, P., "Entre la "Gravedad" y la "Religión": Montesquieu y la "Tutela" de la Monarquia Católica en el primer Setecientos", págs. 1 y 2 , en Jornadas de Historia Moderna,1996. Pagden, A.. El imperialismo español y la imaginación politica. Barcelona 1991, págs. 15. 24 y 25.

BN. MS. 10.695. "Papel presentado a S.M. en 1694", fol. 108

Cabrer Ra. J., Crisis Politica determina el mas florido Imperio. y la mejor institución de Principes. y Ministros. Dedicada al Principe de Asturias D. Luis I. Madrid 1719 
De hecho, a este respecto, resulta significativo el entusiasta y desengañado paralelo que Argüelles, más de un siglo después y a lo que parece precursor del desparpajo soberbio y anacrónico propio de la historia del primer liberalismo decimonónico, establecía entre los momentos previos a la muerte de Carlos $1 /$ y la constitución de las Cortes de Cádiz ${ }^{5}$. Su entusiasmo por la existencia en aquella coyuntura de "un partido numeroso, ilustrado y amante de las instituciones y leyes que protegen la independencia y libertad de la nación, el cual aspiraba a que se reconociera que el derecho de resolver las dudas sobre la sucesión a la Corona correspondía única y exclusivamente a las Cortes generales del reino" ", no lo empañaban las ideas "ultramontanas» y las referencias "místicas» en que sus fuentes se distraian?

Sin embargo, en los meses previos al desenlace frustado y anunciado de la rama hispana de la dinastía Habsburgo, los paralelos eran otros, y las distracciones las mismas. Para don Pedro Portocarrero y Guzmán, Patriarca de las Indias, y Limosnero y Capellán Mayor de su Magestad y su Consejo, los ejemplos sobre los que fundar la prudencia con que se había de gobernar la agonía de su Majestad, para conservación de la Monarquía y aumento de la religión por medio suyo, debían buscarse en la propia historia castellana, o en su modelo ejemplar, la Historia Sagrada ${ }^{8}$. Adaptándose a la forma tradicional, y adecuada, por demás, a la crítica coyuntura, de la conservación de las Repúblicas, la obra trataba en palabras de uno de sus censores de «formar con documentos Christianos, y Políticos, el acertado govierno de un cuerpo civil» ${ }^{9}$, advirtiendo el otro censor que la "policía» era "la parte principal de la Philosophía Moral», para concluir su aprobación apuntando cómo "en este Theatro sólo se representan las máximas más seguras de la Política Christiana, tan afincadas con las Sagradas Letras, el sentir de los Santos, y el apoyo de los mejores Filósofos, Historiadores y Políticos» ${ }^{10}$. Pero esto sin dejar de ser

Afigue I. [.S, A. Examen histórico de la Reforma constitucional que hicieron las Cortes generales y Extraordinarios. Londres, 1853, Impr. Carlos Wood e hijo, Tomo I. Introducción. Debo esta indicación a J. M. Portillo.

AfGutil \& S, A., Examen histórico. tomo 1, pág. 135

El opusculo manuscrito "Lágrimas de los oprimidos españoles" del conde D. Juan Amor de Soria y una obra del Padre Bastida, públicada en Viena por Van Ghelen, en 1703

PORTOCARtiero, P., Theatro Monarchico de Espana que contiene las más puras, como cathólicas maximas de Estado. por las quales, assi los Principes, como las repúblicas aumentan y mantienen sus Dominios. y las causas que motivan su ruyna. Madrid, 1700.

Idem, Theatro Monárchico. “Censura de Don Luis Salazar y Castro, Comendador de Zurita, y Procurador General de la orden de Calatrava, de la Camara de su Magestad, y su Coronista Mayor de Castilla y de las Indias". Madrid 1 de abril de 1700.

:i Idem, Theatro Monárchico, "Aprobación y Censura del Doctor Don Juan de Ferreras, cura propio de la Parrochia de San Pedro el Real de Madrid", Madrid 21 de marzo de 1721. Sobre las 
mérito del tratado no daba razón del mismo. Como reconocía el propio autor, no se buscaba añadir ni contradecir lo ya sabido ${ }^{11}$, bien al contrario sólo se pretendía "mostrar» a los súbditos y "acordar» a los Príncipes «las máximas Políticas y Christianas, con que sus antecesores formaron y enriquecieron el solio". Eran pues razones antiguas y sabidas pero de cuya memoria Carlos II, a quien iba destinada la obra, no parecia necesi$\operatorname{tar}^{1}{ }^{1}$. Sus destinatarios, a parte del resto de los Príncipes “del Orbe Christiano» no eran otros que los súbditos de Carlos II, pues si a este no servia "ni aún para memoria, puede ser que sea útil al público para advertencia". Su motivo parecia hallarse en la ocasión, tercer elemento de la triada que completaban religión y justicia, y no porque supiera el Capellán Mayor del próximo deceso de su Señor, sino por la oposición que con el mismo Tratado se hacía, desemascarando a los «políticos discretos» que no prudentes ${ }^{13}$, que se opondrán a él diciendo que «el tiempo es peligroso, la ocasión poco oportuna, y la verdad siempre odiosa". El Theatro servia como «reprehensión" moral, por política, pues "o reyna la tyrania o reyna la razón». La afirmación se ilustraba, por un lado, con el recuerdo de los últimos godos bajo cuyo reinado "afeminados los vasallos fueron despojo de la tiranía" y al fin cayeron en manos de los musulmanes; y por otro, con los milagros que adornaron las gestas del valeroso Don Pelayo y el recto gobierno de los católicos Isabel y Fernando "quiénes se valieron de la Religión, no por pretexto sino por fin» ${ }^{14}$. En ambos casos la Providencia y la virtud resultaban decisivas, tanto para premiar como para castigar; el milagro necesario ${ }^{15}$. A grandes trazos se contruía una historia ejemplar apropiada a la coyuntura.

El Theatro era una obra compuesta a partir de las máximas, tópicos y razones que, forjados a fines del siglo XVI y comienzos del XVII, habian

implicaciones de dicho encuadre PAGDEN, A., The Language of Political Theory in Early-Modern Europe. Cambridge 1987, págs. 3 y ss.

Idem. Theatro Monárchico. Introdución: "Reconozco la dificultad de sacar a luz puntos tan Politicos, tratados ya con tanta erudición por gravisimos Autores, no teniendo mi trabajo otra cosa, que merezca atención, más que las citas de lo que ellos con tanto acierto enseñaron».

Idem. Theatro Monarchico. Introducción; "sólo V.M. entre todos los del orbe Christiano no recive servicio, ni utilidad alguna de mi corta fatiga; porque adornado de la mayor justificación, la más insigne piedad, y la más puntual asistencia a las tareas del cetro, conoce los medios de adquirir, practica los de conservar, y evita los de perder", siendo las evidentes desgracias que aquejaban a la Monarquía no defecto de su gobierno sino permisión del Rey de Reyes, de lo que hacia prueba el mismo San Luis, tan virtuoso y tan desgraciado en su existencia terrena.

Idem. Theatro Monárchico. Sobre la prudencia. págs. 100 y ss

Idem. Theatro Monarchico, págs. 3-21

Pocock, J. G. A., The Machiavellian moment. Florentine Political Thought and the Atlantic Republican Tradition. Princeton. 1975, págs. 3-79. 
cristalizado en la tratadística castellana que, presente durante la guerra de los Treinta Años, daba razón de la autoexclusión española de los acuerdos de Westfalia. Las firmas que lo autorizaban demuestran el amplio consenso que sus palabras encontraban más alla de las supuestas banderías dinásticas. Su discurso, aunque inoportuno para algunos, era comprendido por todos en la Corte. Era la razón de la monarquia, su razón católica ${ }^{16}$. Seguía siendo el paradigma desde el que hacer política dentro y fuera de España. Era algo más; su razón de ser. Como el mismo autor señalaba, escribia «a cathólicos", lo que le permitía obviar muchas cosas ${ }^{17}$.

Las «discreta política» que denunciaba encontraria abundantes y menos ceremoniosas condenas durante la Guerra de Sucesión, contaminadas claro por la disputa dinástica y la polémica en torno a la validez del testamento: «el miedo de la división de la Monarquía y el error del medio término que hallaron los malos ministros fue la causa eficiente del referido llamamiento" ${ }^{18}$. Un anónimo fantasma de Carlos II relataba en las postrimerias de la contienda cómo le «precisaron a que rasgase el testamento [en favor del Archiduque], por evitar los riesgos del repartimiento, cuyos fragmentos pararon en Francia. Tan sin libertad me tuvieron los atrevimientos franceses, y las cobardias españolas" ${ }^{19}$. Otro "cristiano" figuraba a los "discretos" como afrancesadas hilanderas «tal llamamiento,... no le hizo S.M. sino los Ministros, que pagados de la Francia estaban a su lado fabricando la tela de nra. perdición" ${ }^{20}$. De esta imagen exagerada y panfletaria se hacía eco el propio Argüelles en su interpretación decimonónica de los sucesos: “Su voz [de las Cortes] fue sofocada por las artes y violencia de una facción de grandes y ministros del Consejo Real [que] paso más adelante con su arrojo, procurando intimar y engañar al rey para que otorgase un testamento contrario a su inclinación».

Estos téstimonios legaron una visión deformada de lo que fueron los debates que precedieron a la muerte siempre esperada de Carlos $1{ }^{21}$. Ni la

16) Su forja en contraposición precisamente al discurso politco francés en INuRRITEGul, J. M., La Gracia y la República. El lenguaje politico de la teologia católica y el "Principe Cristiano" de Pedro de Rivadeneyra. Tesis Doctcral, Madrid, Univ. Autónoma de Madrid, 1995.

Clavero, B., Antidora. Antropología católica de la Economia moderna. Milán, 1991. Fernandez Alealadejo, P., «Católicos antes que ciudadanos: gestación de una 'Política Española' en los comienzos de la Edad Moderna". II Ciclo de Historia Urbana, Laredo 1996 [en prensa]; VIF.JO, J., op. cit.

BN, MSs. 6680, "La verdad Cathólica contra un papel que con el nombre de desengaño Cathólico sea difundido por D. I. D. F.", fols. 50-62, (1710-1711).

" Ibidem. "Voces de Carlos II desde el Panteón a sus Vasallos". fols. 1-8. (1709).

Ibidem. "Aviso cristiano. Atalaya de la fe. Destierro de heréticas ignorancias contra el deserigaño Cathólico del Cura de S. Andrés", fols. 63-70 (1710-11)

Para una aproximación a dicha polémica PEREz PICAzO. M. T., La publicística española durante la Guerra de Sucesión. Madrid, 1966. Tomo II. 
capacidad del testamento regio para legar la Monarquía, ni la convocatoria de Cortes, ni la renuncia de la infanta María Teresa a la sucesión española, se encontraban entre las preocupaciones que dominaron las deliberaciones, consejos y memoriales producidos durante aquellos meses.

Todas estas polémicas se vieron desplazadas por el Tratado de Repartición que firmaron el 3 de marzo Francia, Holanda e Inglaterra, y por el que se comprometían en caso de morir el rey católico sin sucesión a garantizar el reparto de su monarquía con el concurso del emperador a quien se invitaba a participar del mismo, señalándole un plazo de tres meses para que diese una respuesta positiva. La noticia llegada a Aranjuez a fines del mes de mayo, donde se encontraba Carlos II gozando de excelente salud, provocó la inmediata convocatoría del Consejo de Estado, además de consultas a diversos ministros y prelados ausentes de la Corte.

Este fue el problema que absorbió los consejos y preocupaciones de los ministros, virreyes y cortesanos de Carlos II, así como de las Cortes de toda Europa. El Tratado se habia firmado sin el concurso del rey hispano ni de parte alguna de la Monarquía que gobernaba. Era el punto de llegada lógico de un camino que arrancaba en la paz de Aquisgrán ${ }^{22}$ y cumplía su ciclo militar el 15 de agosto de 1697 con la entrada de las tropas del duque de Vendôme en la ciudad de Barcelona. El destino de la Monarquia, su conservación, hacía tiempo que ya no estaba en sus manos, su defensa descansaba en el interés que tanto el imperio como las potencias marítimas tenian en contener la ambición de Francia. Estas últimas ejercían ya de hecho una tutela efectiva de su representación en Europa ${ }^{23}$. El sistema de alianzas formado para contrabalancear el poder francés era esencial para la subsistencia y libertad no sólo de los dominios de Carlos II, sino de toda Europa ${ }^{24}$. El Tratado, deshaciendo la coalición, desanudaba sus destinos destruyendo la Monarquía Católica. La paz, las nuevas virtudes civicas, el espíritu político y tolerante que se extendia por Europa y sobre todos, el comercio que las difundía y de las que dependía, daban razón del inesperado Tratado.

\footnotetext{
Viejo, J., "Grocio Católico". Orden europeo y Monarquia Católica durante la Guerra de Devolución, 1667-1668. Tesis Doctoral, Madrid, Univ. Autónoma de Madrid, 1994.

AHN, Estado, leg. 673: Consulta del Consejo de Estado de 8 de junio de 1700 (de oficio): "Carta Fco. Bernaldo de Quirós 28 de abril: Motivo del tratado: las noticias que habían corrido de la falta de salud de V.M. y conocimiento en que se hallan todas las potencias; de lo desprevenida de fuerzas de esta Monarquía, para defenderse en qualquier accidente».

Sobre la recepción de este nuevo paradigma en territorios de constitución católica PAGDEN, A., "Fede Publica' y 'Fede Privata': confianza y honor en el Nápoles Español», págs. 107-141, en op. cit.
} 
Desde los presupuestos culturales que informaban las razones de la Monarquia Católica sólo podia ser obra de herejes o "políticos atheistas". El rechazo del Tratado, aparte de la enormidad que desde la perspectiva jurídica suponia disponer de los dominios ajenos sin contar con la voluntad del testador, mucho más estando aún este vivo, y aunque maltrecho, sano y joven, $y$ del escarnio de hacerlo público, se presentaba como una obligación en conciencia ${ }^{25}$. El único argumento manejado más allá del honor y la conciencia para oponerse al Tratado desde el Consejo de Estado en la correspondencia diplomática, asi como en los memoriales pedidos o espontáneos producidos a su estela, no tenía más razón que la disminución de la Iglesia en las Indias por las compensaciones que supuestamente recibirían ingleses y holandeses a cambio de su aval, esfuerzo y garantía. Dichas compensaciones territoriales y confesionales nunca existieron, sin embargo, la ruptura de la alianza resultaba inimaginable sin ellas ${ }^{26}$. El comercio y sus virtudes no entraba en sus cábalas. Además, la ruptura de las relaciones con las potencias marítimas por el asunto Schoemberg ${ }^{27}$ dificultaba cualquier resistencia diplomática que contrarrestase por las vías ordinarias la inicitiva francesa y reconstruyese la confianza.

Hasta ese momento el pleito sucesorio estaba pendiente tanto del difícil, pero no imposible, embarazo de Doña Mariana, como de que se presentase una oportunidad para trasladar al Archiduque austriaco hasta la Corte de Madrid, lo cual, aparte de las desconfianzas mutuas que habian crecido desde la ruptura que había supuesto la Paz de Westfalia, confirmada desde entonces por numerosos desencuentros, estaba impedida por la permanente amenaza de Luis XIV que no perdía ocasión de recordar lo consideraría como una declaración de guerra, lo que hacía aparecer dicho traslado como inoportuno o inconveniente, aconsejándose esperar siempre a un mejor momento.

AHN, Estado. Leg. 673/2: Consulta del Consejo de Estado acordada el 7 de julio de 1700. dada el 8. Conde de Frixiliana: expone su voto de 29-30 de junio; "pero que nunca cree. que quando la necesidad de la defensa del honor y la conciencia de defender los Reynos que se poseen se puede considerar en una total imposibilidad de vencer hasta que encuentre con ellas, la diligencia de superarlas, se quede disculpado con Dios, y con los hombres; Que ser conquistados es el mayor mal que puede suceder, pero a su juicio menor que el de rendirse. .... Hasta los venecianos se inclinaran de nuestro lado en defensa de nuestra libertad". Villafranca: "Que el único medio es el que el Consejo ha consultado a VM assi para salir aora de los riesgos de la guerra como para cumplir VM con lo que deve en justicia y en conciencia que se haga cuanto antes. ..."

AHN, Estado, leg. 673, Consulta del Consejo de Estado de 8 de junio de 1700 (de oficio) Santiesieban: "... Hacer notar a Luis XIV el perjuicio de la Religión, dando por sentado que el Tratado equivale a entregar las Indias en manos de Ingleses y Olandeses."

Maufa, G., Vida y Reinado de Carlos /l. Madrid, 1990 (ed. orig. 1954), págs. $450-452$ 
Si en las consultas que siguieron al Tratado de Repartición se trató de la sucesión, fue porque según explicaron los consejeros de forma casi unánime resultaba imposible decidir una política diplomática y militar coherente sin saber previamente quién iba a ser el designado por Carlos II. Dando por hecho la imposibilidad absoluta en que la Monarquía se encontraba para afrontar la oposición al Tratado sola, la política de alianzas que debia urdir para resistir el que se le impusiese una solución "tan perjudicial para la causa de la Iglesia", debería contar con este dato previo. De este modo la sucesión se convirtió en el primer objeto de las consultas del Consejo de Estado. La resistencia de Carlos II a decidirse paralizó cualquier iniciativa, salvo la formal protesta que pudiese haber sido intentada desde Madrid y la consulta de la consulta a Roma ${ }^{28}$. Los despachos diplomáticos tentaban soluciones, alianzas e intuían conspiraciones a la espera de una orden que nunca llegaba.

La consulta favorable al duque de Anjou era en primer lugar la única salida que, salvo la defensa armada, considerada inviable frente a Francia, podía forzar a las potencias maritimas a romper compromiso con Francia y volver a servir de paraguas protector de la Monarquia Hispana permitiéndole decidir su sucesión con libertad ${ }^{29}$. En segundo lugar se presentaba como la única que, de producirse evitaba la conquista de al menos parte de la Península, librando formalmente a los castellanos y aragoneses de verse sometidos a la soberanía francesa, permitiéndoles conservar sus

AHN, Estado, Leg. 673/2: Consulta del Consejo de Estado acordada el 7 de julio de 1700 , dada el 8 (de oficio): "El Consejo en vista de lo que V.Magd se sirve mandar en el referido papel que habiendo conferido en razón de su contenido representa a V.M. que no haviendo V.M. tomado resolución en lo principal de esta materia. No puede idearse respuesta alguna porque de lo que V.M. determinare ha de resultar la respuesta que se diere al Sr Emperador y a su embaxador. VM Mandará lo que fuere de su Real agrado"

BN, MSs. 6774: Consulta a S.M. de 10 de julio de 1700: «añadir V.M. que ve muy resueltos a sus Reynos, y vasallos de defender a todo trance la misma Yntegridad y teme por consiguiente que antes por salvarla, admitirán por sucesor de V.M. a un segundogenito del Delfin (bien que sea con natural repugnancia) que al Sr Archiduque (bien que tan amable y deseado) si ha de ser a costa de tan odiosa laceración de la Corona. Convendria jugar esta misma pieza con Yngleses y Olandeses; porque si liegan a persuadirse que V.M. y sus Reynos, son capaces de hacer esta resolución, y la de ceder los Payses Bajos a la Francia, entrarian sin duda en muy molesta aprehensión y mayormente no pudiendo dejar de reconocer que para este gran paso no son necesarios los exércitos, ni Armadas. que no tenemos, más vasta un sólo acto de voluntad de V.M. y de sus Reynos, que el Rey Christianisimo seria tal vez capaz de abrazar el partido; y burlarse del tratado que acaba de concluir", fol. 24v. En el mismo sentido AHN, Estado. leg. 736: Consulta del Consejo de Estado de 8 de junio de 1700 (de oficio): Santiesteban: «... los remedios ...ya están provados y experimentado su logro y el de armarse, como dice Quiros, es oy idea fantástica, sin medios ni aún tiempo para ello .... Hacer notar a Luis XIV el perjuicio de la Religión, dando por sentado que el Tratado equivale a entregar las indias en manos de Ingleses y Olandeses. Ynsinuandoles que V.M. no les excluye de la sucesión, no teniendo S.M. descendencia. ... solicite las fuerzas a Olanda y Britania para testar con libertad. Al Emperador escrivir en defensa de los intereses de la Augusta Cassa.". 
costumbres y libertades. Todo ello bajo la coacción que suponía el Tratado de Repartición. La elección del candidato francés era una necesidad impuesta por las circunstancias, que nadie quería, pero que todos comprendían como el único camino que podia restablecer el orden europeo que habia permitido sobrevivir a la Monarquía Católica con poco más que sus palabras. La distancia física que separaba a las dos ramas Habsburgo hacia imposible dicha opción ${ }^{30}$. Los ofrecimientos del emperador de guarnecer los territorios italianos de la Monarquía producian más desconfianza que alivio ${ }^{31}$, además de que no resolvian el problema principal: ¿quién defendería los Pirineos cuando la meta a alcanzar por las Tropas francesas era Madrid? ${ }^{32}$. Como afirmó Montijo en su voto de 14 de septiembre "lo principal es España, cabeza de la monarquia, y que si ésta se pierde se pierde todo, por lo que la oferta del emperador parece bien pero es insuficiente". Carlos II estaba obligado en conciencia a ello tanto como sus consejeros, como último reducto de su obligación católica ${ }^{33}$.

AHN, Estado. Leg. 673/2: Consulta del Consejo de Estado acordada el 7 de julio de 1700. dada el 8 (de oficio): El Consejo Votos: Manzera: "Señor siendo común a los buenos vasallos y Ministros de este Consejo la natural inclinación y obligación a la Augustisima Cassa, ay en el que vota, particularisimas razones para esto. La de haver servido tantos años a la Reyna Madre [honrras, embajadas en Viena, matrimonio alemán] motivos todos que militan a sincerar la ingenuidad de su opinión, pues es cierto que en igualdad de esperanzas, y de riesgos, nadie pensara antes en un hijo de Francia, que en un Archiduque de Austria".

VIEJO, J. op. cit., págs. 10-13. PEPGEN, K., "Ferdinant III", págs. 159 y ss, en Die kaiser der Neuzei. 1519-1918t, SCHINOLING, A y ZieGLer, W., (ed). Munich, 1990.

AHN, Estado, Leg. 673/2: Consulta del Consejo de Estado acordada el 7 de julio de 1700, dada el 8, de oficio: El Consejo Votos: Portocarrero: "dice que la monarquia no tiene fuerzas que oponer ni en las fronteras, que el Emperador ofrece poco. 20 mil hombres y sólo para ltalia, que Génova y Venecia no darán los baxeles y que la única solución es la que ya le propuso en con. sulta pasada. ... haze memoria a V.M. que el único medio y remedio es el propuesto por este Consejo para la restauración de esta tan integra Monarchía sintiendo muy cordialmente verle en un mes que ha que se voto este negocio corroborado el dictamen con que las personas de grado y condición de otros Reynos súbditos de VM lo han llegado a entender".

33 AHN, Estado, Leg. 673/2: Consulta del Consejo de Estado acordada el 7 de julio de 1700, dada el 8 (de oficio): El Consejo Votos: Manzera: "pero la ley de Dios, la fidelidad a V.M., el amor a la Patria; y la deuda a su propio nacimiento, le necesitan a posponer la sangre y la carne, a lo que entiende con su limitada capacidad. Confiesa la contingencia de que un Rey de Francia no admita la Monarchia para un Nieto, aunque ay razones que nos alientan a esperarlo; y en este caso consiguiéramos perpetua la monarquía en su integridad que tanto importa. Sino se eligiese el medio de ofrecersela, es inevitable su división con que es innegable consecuencia, que en lo primero nos arriesgamos y en lo segundo nos perdemos de conocido. Pensar que en el estado del Patrimonio y de los súbditos aya nervio para salir al encuentro al impetu y superior poder de Francia, es poco menos que tantasía quimerica, pues como dijo el Marques en el voto citado, ni VM tiene hacienda, ni los vasallos esprimidos en una prensa, pueden dar sustancia que cubra la menor de tantas urgencias, como se necesitan, aún para una mediana defensa, fuera de que duda mucho el que vota que con suma conciencia sea lícito acabar de destruir los vasallos, sin alguna probabilidad, y aqui no ay, ni aún remota de que la ultima sangre de sus venas aya de redimirlos de los estragos, y desolación que los amenaza". 
En este contexto politico ni las Cortes que echará de menos Argüelles cabian, ni tampoco la habitual Junta de Teólogos y Juristas reunida, años atrás para tratar de la sucesión, ni siquiera el Consejo de Castilla ocupaba el centro de la decisión. No se trataba de decidir sobre la sucesión, sino de contrarrestar un Tratado de Repartición que resultando intolerable para el honor y conciencia castellanos, muy conveniente para la paz y el comercio europeos, y que colocaba a Castilla en una situación extrema ${ }^{34}$. No se trataba de elegir un sucesor sino de evitar una invasión y conservar una constitución fundada en religión ${ }^{35}$. Por eso la consulta que había de absolver y asegurar la conciencia Real no se consignó a una de estas Juntas sino que por tratarse de contrarrestar los efectos del Tratado de Repartición se acudió al $\mathrm{Papa}^{36}$, como cabeza del instituto que habia de padecer los perjuicios del mismo: la Iglesia ${ }^{37}$. Como le escribió el propio Carlos el 13 de junio de

4 AHN, Estado. 736; Consulta del Consejo de Estado de 8 de junio de 1700 (de oficio): Santiesteban: “... los remedios ...ya están provados y experimentado su logro y el de armarse, como dice Quiros, es oy idea fantástica, sin medios ni aún tiempo para ello ... quando S.M. se balga de aquellos medios que la prudencia y las reglas del govierno dictan, no llevando más fin que el del cumplimiento de la obligación acia el bien de sus Reynos, y mayor servicio de nuestro Señor. Su divina Magestad le asistirá de manera que se logré sin duda el mayor acierto".

AHN, Estado. Leg. 673/2: Consulta del Consejo de Estado acordada el 7 de julio de 1700. dada el 8 (de oficio): Manzera: "... [ es imposible que el Rey de Francia] desechará una joya tan estimable, para un pariente tan próximo y sin los gastos ni los peligros de adquirirla por la espada; .... $4^{\circ}$ Si repulsa [sic] el Rey de Francia nadie puede decir que S.M. no lo ha intentado, habrán comprendido estos vasallos y Reynos, el paternal amor con que VM a procurado redimirlos de la esclavitud de Francia, que es un punto nezesarisimo en la constitución presente, y se desemgañaran los Reyes, Principes y Repúblicas de Europa, de que los bastos desinios [sic] del Rey de Francia no se contienen dentro de lo razonable, aspirando a la Monarchia Universal, y que a este proposito se encamina la idea de agregar la Monarchía de España a la de Francia; y si este co. nocimiento no los despierta del letargo que oy duermen será notoria evidencia de que ay sobrenatural impulso que lo dispone así, en castigo de nuestros pecados e injusticias, y no sería el menos aspero y severo, permitir que en nuestros tiempos y en nuestras manos se perdiese la Religión Cathólica en las Indias".

AHN, Estado. Leg. 673/2: Consulta del Consejo de Estado acordada el 7 de julio de 1700 , dada el 8, de oficio: EL Consejo “Señor, En la consulta inclusa de 8 del pasado (junio), motivada de lo que ocurrió con ocasión del tratado ajustado entre Francia, Ynglaterra y Olanda sobre la sucesión y división de esta Monarquia se sirvio V.M. responder lo siguiente: Quedo enterado de quanto el Consejo me representa en este tan primero como gravisimo, universal e importante negocio y para seguridad de mi conciencia, de mi obligación, del bien de mis vasallos, de la subsistencia de mi Monarquía; y de la entera unión de todos sus Reynos, he querido participarle al Papa; ... es estoy aplicado a procurarlas mayores providencias para la defensa de estos Reynos, con la cautela que conviene al presente".

AHN, Estado. Leg. 673/2: “Consulta del Consejo de Estado acordada el 7 de julio de 1700, dada el 8 (de oficio): En el margen, El Rey “... quiero tener presente to que responde el Papa a lo que le tengo escrito, como lo previne al Consejo en la resolución de la Consulta de ocho del Pasado (la del 6 de junio) ...". MAURA, G., op.cit. pág. 626: Alude Carlos II en su misiva al Pontifice a "las copias inclusas, de que también se infiere la gran parte de la Christiandad que en las Indias y algunas islas se repartirán, juntamente ingleses y holandeses". 
1700 a instancias del Consejo de Estado: «he querido ofrecer a Dios en su Iglesia el sacrificio de la propia voluntad, poniendo, como lo hago, mis resoluciones y mis Reinos en las santas manos de Vuestra Santidad, para que ...sea Vuestra Santidad quien dirija mis operaciones ...con su mediación suprema y con la infalible verdad de su determinación " ${ }^{38}$.

Se trataba de que la institución monárquica subsistiera y prestase de nuevo su servicio de procurar un sucesor. Evitando la conquista, Francia recibía un cuerpo completo, un mayorazgo que administrar, no un territorio que patrimonializar. Se trasladaba la tutela de las potencias marítimas a una potencia cercana, católica y eficiente, además de desterrarse un enemigo mortal.

El Tratado de Repartición debia ser rechazado por honor y religión: razón católica ${ }^{39}$. La resistencia pasaba por perpetuar la situación de contrabalanceo en Europa, con eso se jugó antes y durante la guerra. El mantenimiento de la identidad en espera de tiempos mejores ${ }^{40}$. Por última vez la Monarquia Católica impuso su política y su interés a Europa, decidió cuando todos la consideraban incapaz de hacerlo. La razón Católica funcionó, imponiéndose a la razón dinástica, de estado y familia. De ello parecía haber sido consciente el mismo Carlos II, cuando una vez muerto el elector de Baviera y frustrada así su primera elección, declaró en un Despacho que «si el Tratado de repartición proseguía adelante, aunque se apartase de todas las máximas de sus mayores, llamaria a un príncipe que tuviese su sangre, pudiese mantener unida la Monarquia". Por que como el propio Portocarrero le había recordado desde el Consejo de Estado: “El monarca no era el amo, sino el usufructuário de la Monarquía» "1.

Éstas eran las razones de los «discretos". Para los prudentes, presentes aún en el Consejo, no cabia otra salida que intentar la defensa armada, la alianza con Italia y el emperador, en la confianza de que el tiempo deshiciese alianza "tan contra natura» "2?. La facilidad y desvalimiento con

\footnotetext{
Maura, G., op.cit., pág. 626
}

Fernandel. Santamaria, J. A., Razon de Estado y politica en el pensamiento politico español del Barroco (1595-1640). Madrid, 1986, págs. 9-77. Clavero, B., Razón de Estado, razón de individuo, razón de historia. Madrid, 1991, págs. 15 y ss. Inurritegui, J. M. op. cit.

"Sobre su identidad Clavero, B., Antidora, passim. Flanandez Al.baladejo, P.. Fragmentos de Monarquia. Madrid, 1992.

AHN, Estado, Leg. 673/2. Row N, H.H., The King's State. Property Dynasticism in Early modern France. Págs. 75 y ss. New Jersey, 1980.

AHN, Estado, Leg.367/1; Consulta del Consejo de Estado de 11 de julio de 1700 ide oficio)45: Consejo: Fuensalida: Que VM se arme; "que S.M. recupere el tiempo perdido y forme un plan de la forma que pueda defender sus Dominios en todos los acaecimientos especialmente de los alentados que se pueden temer de la poca fe de franceses y lo adelantado que se ve el em- 
que nos entregábamos en manos del candidato francés sólo conseguíria aislarnos del resto de Europa y quedar bajo la absoluta dependencia del francés, que, a corto plazo, volvería la sucesión, conquista ${ }^{43}$. Las experiencias e imágenes que del gobierno de Luis XIV se tenía en la Monarquía Hispana no avalaban en absoluto la confianza de que una vez el duque de Anjou en el trono católico fuese a respetar los suaves modos de la Casa de Austria ${ }^{44}$. Los vaticinios que Leibniz hiciera en 1703, venian a pronosticar desastres similares ${ }^{45}$. El ataque contra el Consejo de Estado

peño del Rey Christianisimo, no escusando decir a V.M. que se apresure y asi ganará alianzas. Mandense embajadas a Inglaterra. Holanda y Venecia y suscitese alianza en Ytalia".

AHN. Estado Leg. 673/2: Consulta del Consejo de Estado acordada el 7 de julio de 1700 , dada el 8, de oficio: El Consejo Votos: Conde de Frixiliana: « .. siendo infalible que nada importa tanto como la unión de ellos [los territorios de la Monarquia]. Pues no quedando dividida la monarchía no tendria yo repugnancia a la opinión que llevan los prudentes juicios que siguen ésta; a donde se para mi consideración, a los siguientes reparos, que me hacen dudoso, sino incierto, el medio que se toma tan desierto de autoridad. como persuaden las pocas fuerzas con que se halla V.M. Rezelo que si en este caso (la oferta al segundogénito de Francia) tiene VM alguna repulsa (alguien en Francia se opone, o en Europa con suficiente fuerza), se halla más sólo, que le considero aora, pues todos los que pretenden asistirles, procuraran concertar sus intereses de suerte, que VM no tengo donde volver los ojos.... Los presupuestos que ocurren, y a mi el que arrostre nuestra oferta, es la propia docilidad con que entramos en ella sin alguna autoridad de fuerzas y aliados que le expongan dudoso su intento y con que venzer el forzoso cumplimiento que habrá menester (a su juicio) por el de este contrato. pues la liberalidad de ceder Reyno, es tan desmedida aún para práctica entre padres y hijos que sólo se vió en la cadente hedad del Sor Emperador Carlos V y en su timorata conciencia

Quedame la ponderable segunda parte de que aquellos vasallos que exaltaron con su espada y su Consejo al Christianísimo al elevado paraxe de dividir Reynos, formarian una perjudicial contra su dueño que privaba a sus súbditos y nación de la gloria y utilidad de haver aumentado aquella Corona, reynos que havian de mandar por la sustituzion de sus Leyes. Siendo esto así, si el medio que se elixe no quedase excluido por estos fundamentos. Donde quedaba recurso con que resistir parte alguna de estos dominios. a quien havía pensado en preservar unido el todo de ellos? Con que consejo guiariamos las máximas? Con que fuerza extraña nos sufragariamos para mantener las opiniones? Luego sin aversión a nación (en los términos de quedar con Rey propio) no son desamparables estas consideraciones antes para mi la fuerza de ellas estimula mi obligación. Siempre que se prevengan estos casos, siempre que se halle solución a ellos, lo que yo deseo, será lo que convenga al bien del servicio de VM y del Estado. Quanto dificulta la manutención de este se supone es falta de medios: quien entrare a poseherle por la perdida de ellos, buscará los caminos para mantenerle, y no será muy duro que quien se halla dueño de él, para conservarle execute (con más equidad que se practicare entonces) lo que convenga a esto. No pierdo de vista la falta de exércitos y armadas con que VM se halia ... Avista de todas estas consideraciones juzgo que es muy digno de profunda reflexión en qualquiera de los dos casos, de admitir o repugnar el Christianisimo, tener presentes los efectos suzesivos y facultad con que ellos queda el govierno para el Consejo y las operaciones que devan tomarse ...". Y en RAH 9/652; fols. 3r: "que ahora del Rey de Francia que con oficios publicos lo divide y reparte a su arbitrio no sólo no se quexan pero en premio de tan alta injuria a la Dignidad de SM y a toda la Monarquia le ofrecen la voluntaria esclavitud del Rey Nro Sr y de sus Reynos suponiendo que en el nombre se ofrece al nieto y en la realidad al mismo Rey como nadie ignora".

RAH 9/651: Sobre la sucesión de un Príncipe de Francia en la Monarchía de España. Madrid, 1700

LEIBNı, G. W., "Manifiesto en defensa de los derechos de Carlos III, Rey de España, y de los justos motivos de su expedición, 1703", en Escritos de Filosoria juridica y política, ed. J. SALAS. Madrid, 1984, págs. 291-323 
se desató en este contexto. Se invocó el fantasma del gobierno republicano para descalificarlo comparando a sus miembros con el Senado de Venecia o el Parlamento inglés, como una oligarquía política que pretendía coaccionar la voluntad del monarca en favor de sus intereses, arrebatando al mismo tiempo a las Cortes o magnates del Reino sus prerrogativas: "haré breve definición de lo que es el Consejo de Estado, porque recojan las alas de su altanería ... intentar que el Rey se haya de conformar a sólo su influjo, abrogándose las prerrogativas de el Parlamento de Ynglaterra $u$ del Senado de Venecia con su Dux ... ${ }^{46}$.

Sin embargo las distancias no eran tantas, unos y otros compartian un mismo paradigma: el Católico. Como aputaba Frigiliana en su voto de 14 de agosto "si tardamos en las negociaciones y diligencias, haremos almoneda de todo el caudal que podemos haver tenido, quedaremos sin ventaja y sin disculpa para el partido que huvieramos considerado ...y en suma nos perderemos sin disculpa para el honor y conciencia» ${ }^{4}$ ?

Entre éstos, si se suscitó algo del espíritu gaditano que Argüelles quiso ver en la ruptura dinástica, aunque ajeno por completo a los tributos liberales que él supusiera. En nombre de la conciencia y el sentido común que Frigiliana invocará, un anónimo papel encadenaba la obligada resistencia al Tratado, para como se decía poder decidir sucesor en libertad con una especie de ejército popular: "...las ciudades y pueblos de este continente sólo tienen para formar exércitos de cien mil hombres si que hagan falta a una vez de su Magestad ...ay tesoros que se ofrecerán voluntariamente sabiendo que se han de concurrir en mantener la honra y la inestimable libertad y quando faltasen caudales (que sobran) cálizes ay en las Iglesias que los mandaba Dios para defender su causa» "48. Éste, por supuesto, sólo sería posible previa reforma del gobierno de la Monarquía en sentido despótico: «...el antídoto es conocido, mudar mano y dexar ca-

BN. Mss. 10.919 "Reflexiones sobre el Estado presente de las cosas de Europa y esta Corte, con el motivo de la repartición de la Monarquia; descubrense las verdades en defensa de la inhocencia perseguida, que la malicia ha tenido ocultas y otras circunstancias dignas de la común inteligencia", fines de 1700 , págs. 97 a 118. En el mismo sentido, RAH 9/651: Sobre la sucesión : "quien pudo soñar que una cosa tan estrañamente grave se avía de resolver al arbitro de seis hombres privados, aún sin acordarse de la natural combocación de unas Cortes, gentes donde el concurso universal de la naciones solicitas se el maior acierto y fortificasse con su consentimiento la resolución? ...es de saber que hasta que en España entró la suabe dominación de la Casa eran consejeros del Rey, y asi entendian en las materias de Estado y de govierno, todos los prelados, las dignidades seculares y los titulos, los quales aun retienen por honor el nombre de Consegeros y el asiento en los Tribunales"

AHN Estado, leg. 673/2: Consulta del Consejo de Estado de 14 de agosto de 1700 (de oficio).

En el mismo sentido en RAH 9/652; fol. 4 r. 
mino que ha llevado ... que ya no es ocasión de muchas consultas y conviene escarmentar de sus malos efectos; sepa el mundo que se muda la planta infeliz del gobierno y que S.M. resuelve por sí sólo" ${ }^{49}$.

Como ni la reforma se produjo, ni el ejército existió, la aceptación por parte de Luis XIV del testamento ${ }^{50}$ puso en marcha un discurrir de los sucesos que, si en un principio pareció dar la razón a los prudentes, acabó avalando la apuesta de los discretos. La confianza ${ }^{51}$ sólo se quebró cuando el pacto se rompió poco después de llegar Felipe $V$, que recibido en clave confesional como futuro conquistador de Jerusalén y regenerador de la gloria de la Monarquía, quedó muy pronto bajo el dominio de su abuelo ${ }^{52}$. La tutela francesa, bien por la guerra o por propia voluntad, se trasladó al interior de la constitución castellana modificando la costumbre e imponiendo de forma autoritaria una relación de dependencia, cumpliéndose los más negros augurios de la víspera ${ }^{53}$. La inquietud que esto produjo en el interior de Castilla prendió la llama de la guerra en la Península. Una quiebra de la confianza en el interior y la absoluta dependencia de los designios de Francia en el exterior rompieron el consenso sucesorio que no se restableció hasta 1709 cuando Castilla volvió a recuperar el paraguas de las potencias marítimas, obligando a Felipe $V$ a un progresivo alejamiento del gobierno francés y la recuperación, finalmente, de las señas de identidad de la Monarquía tanto en el interior a partir de 1715 , como la recuperación de su personalidad en el exterior, que forzó la formación de la cuádruple alianza en su contra. Así, al mismo tiempo que se presentaba a Felipe $V$ como un monarca providente querido por Dios, que habia sido asegurado de modo milagroso en el trono de España a semejanza de los grandes Patriarcas y Reyes de las Sagradas Escrituras, se denunciaba la "política" ajena a la más elemental justicia moral que presidía la actuación de las potencias en el exterior contra España ${ }^{54}$.

De este modo se podian describir en una instrucción formada en los aledaños del Imperio, compuesta originalmente en francés, en 1759, los in-

RAH 9/652; fols. 2-4V

AHN. Estado, leg. 2552

HEFMAN, A. L.. "The Language of Fidelity in Early Modern France", págs. 7 a 21 , en The Journal of Modern History. 67 (marzo, 1995), págs. 1 a 24. HE SPANHA, A. M. "La economía de las gracias". pags. 151 a 176 en La Gracia del Derecho. Madrid, 1993.

BAUI3H!I LARI, A. Philippe $V$ et la Court de France. Paris 1890, vol. 1

Para lo que sigue VICENT. I. M. "Felipe V y la Monarquía Católica durante la Guerra de Sucesion: una cuestión de "estifo" ". Espacio. Tiempo y Forma. Madrid, 1994, págs. 397 a 422.

Montanche?, A., Avisos Morales y Politicos para principes, eclesiasticos y militares Dedicados al Serenisimo Señor Luis Primero. Valladolid, 1721 
tereses políticos que la Monarquia española tenía en Europa, sólo movidos, aún, por razón de Religión.

La historia de dicha sucesión, deudora de los debates producidos durante la Guerra y contagiada por la grandeza de Luis XIV, trasmitida por los despachos diplomáticos en nuestro caso ${ }^{55}$, discurre sin embargo por otros caminos ${ }^{56}$. Para la interpretación clásica el Consejo de Estado no sería más que la envoltura institucional utilizada por el partido profrancés en la Corte de Madrid para imponer al moribundo Carlos II, al duque de Anjou como heredero. Dicha violencia sería el último eslabón de la política seguida por Luis XIV hacia la Monarquía Hispana, salpicada de guerras, conquistas, tratados de partición e intimidaciones diplomáticas. La voluntad española de conservar la Monarquía en su totalidad y la supuesta popularidad que la sucesión francesa tenía entre la población hacian el resto ${ }^{57}$.

De forma consecuente el hilo conductor que hilvana el relato de los últimos años del reinado de Carlos 11 lo forman las visicitudes de los dos partidos de corte dinástico, cuyos enfrentamientos cortesanos por ganar la última volunta de Carlos II tuvieron su lógica continuación en la Guerra de Sucesión. Aun así las dificultades para encuadrar dichos partidos son enormes. Más parece que son ilusión de esta historia que realidad del pasado. En las listas elaboradas por el embajador imperial o francés los nombres se repiten apareciendo para unos declarados imperiales y los otros fieles franceses ${ }^{58}$. La correspondencia diplomática y las conversaciones palaciegas delatan la confusión absoluta que existía a este respecto aún para quienes debian estar, como protagonistas, más enterados sobre quién era quién. Ni siquiera la Reina, cabeza natural del partido alemán junto al embajador Imperial, estaba libre de sospechas. El juego del disimulo cortesano, tan necesario en coyuntura tan indecisa, se sumaba a la inexistencia de un valimiento claro que jerarquizase el patronazgo en la

MIGNET, M. Negociations relatives à la Sucession d Espagne sous Louis XIV. Paris, $1888-$ 1892. (4. vols.).

Es excepción Maura, G., op. cit.

KaMe N. H. La Guerra de Sucesión en España. Barcelona 1974. págs. 11-15.

AHN, Estado, leg. 673, Consulta del Consejo de Estado de 8 de junio de 1700 (de oficio): Santiesteban: En Paris se esta seguro "de no poder esperar nada a favor de sus nietos en esta Corte y que las voces que se suelen esparcir de tener en ella parciales de la Francia, no han tenido más fundamento que desacreditarse entre si los partidos de cortesanos y Palaciegos para sus fines y pretensiones particulares...". 
corte configurando clientelas más o menos estables desde la salida de Oropesa de la gracia Real ${ }^{59}$. El único punto de referencia lo constituía la Reina y su camarilla hacia la que se demostraban filias y fobias, desde mucho antes de que el asunto de la sucesión se declarase. La oposición declarada del Cardenal Portocarrero desde al menos 1696 estaba dirigida contra el gobierno que alentaba la reina, no contra las supuestas preferencias sucesorias que ésta pudiera alimentar ${ }^{60}$. La asignación de papeles de austracistas y felipistas se realizó a posteriori, según el papel que cada uno jugó tras el ascenso al trono del de Anjou. Baste recordar que el Consejo de Estado que decidió el testamento estaba formado en su mayor parte por lo que se conoció como la hornada del padre Gabriel confesor de la Reina ${ }^{61}$.

Benigno, F., La sombra del Rey. Madrid, 1994, págs. 9-35. Kettering, SH., "Patronage and Kinship in Early Modern France", French Hisytorical Studies, 17. $n^{\prime \prime} 2$ (1989), págs. 408-435.

BN. Mss. 10.889; "Memorial muy curioso que dió a S.M. el cardenal Portocarrero a 28 de diciembre de 1696 ", fols. $185 \mathrm{v}$ y ss.

Maura, G., Vida y Reinado de Carlos II. Madrid. 1990 (ed. orig. 1954), págs. de la 543 en adelante. 